ziation mit den klinischen Daten: Heuschnupfen-Kinder fanden sich eindeutig häufiger in Familien, die nun vermehrt Margarine verwendeten. Umgekehrt fand man eine inverse Beziehung zum Butterkonsum. Der Verbrauch von Margarine in der früheren DDR hatte wesentlich niedriger gelegen als im Westen Deutschlands (35\% vs. 67\%). Die gefundene Korrelation blieb auch noch signifikant, nachdem man Atopien in der Familienanamnese, sozioökonomischen Status, Anzahl von Geschwistern, Heizart sowie Tierhaltung in der Auswertung berücksichtigte.

Im letzten Jahr war von einer anderen Arbeitsgruppe postuliert worden, daß eine hohe Zufuhr bestimmter mehrfach ungesättigter Fettsäuren wie Linolensäure ein Risikofaktor für die Entwicklung von Asthma und Allergien sei. Über die Steigerung der Synthese von Prostaglandin E2, so die Hypothese, könnten sie letztlich die Bildung von IgE fördern. Margarine enthält bis zu 20mal mehr Linolensäure als Butter. Möglicherweise sind solche Veränderungen beim Fettkonsum allerdings lediglich Marker eines Wandels im Gesundheitsbewußtsein oder anderer Einflußfaktoren. Die in dieser Untersuchung erhobenen Daten stützen zunächst jedoch diese These, die es nach Ansicht der Autoren wert ist, weiter untersucht zu werden.

\section{Erklärungsansätze für nicht gestiege- ne Asthmaprävalenz}

Daß die erhöhte Sensibilisierung gegenüber Hausstaubmilben nicht mit einem Anstieg der Asthmaprävalenz verbunden war (s. Kasten), könnte nach Mutius et al. unter anderem so gedeutet werden, daß die frühe Sensibilisierung weniger Ursache für Asthma als vielmehr Intermediär-Stadium in der Pathogenese der Krankheit, also Prädiktor ist. Es ist aber auch die Schlußfolgerung möglich, daß eine Sensibilisierung gegenüber Milben sehr früh im Leben oder aber die Allergenbelastung sehr hoch sein muß, um die Entwicklung eines Asthma anzustoßen.

(wpa)

Quelle: Von Mutius E et al.: Increasing prevalence of hay fever and atopy among children in leipzig, East Germany. Lancet (1998); 351: 862-66.

\title{
Birkenfeigen-Allergie: Angioödem nach Verzehr von Feigen und Kiwi
}

\author{
Die beliebte Zimmerpflanze Ficus benjamina kann nicht nur \\ allergische Sensibilisierungen hervorrufen, ihr relevantes Allergen \\ neigt auch zu Kreuzreaktionen mit Kiwis und Feigen.
}

W enig erinnert am „Laubbaum“ Ficus benjamina daran, daß er zu den Maulbeergewächsen (Moraceae) gehört und damit mit dem „Fruchtbaum" der Feige verwandt ist. Eine Kreuzsensibilisierung beider Pflanzen ist jedoch möglich. Das relevante Allergen ist das Enzym Papain im Milchsaft der Birkenfeige, das auch im Latex der Kautschukpflanze enthalten ist.

\section{Ficus-Allergie seit 1985 bekannt}

Eine Sensibilisierung auf Ficus benjamina wurde erstmals 1985 beschrieben. Zwei Arbeiter einer Begrünungsfirma, beide Atopiker, entwickelten eine Rhinkonjunktivitis und AsthmaAttacken. Damals wurden spezifische IgE-Antikörper gegen Extrakte aus Laub und Zweigen der Birkenfeige nachgewiesen. Spätere Untersuchungen in vier Firmen zeigten, daß nicht weniger als 26,6\% der Beschäftigten im Pricktest positiv gegen Ficus-Latex reagierten.

Wenig später wurden auch bei nicht-beruflich exponierten Personen Sensibilisierungen diagnostiziert. So wiesen 1987 in einer schwedischen Untersuchung $3,3 \%$ von privaten Ficus-Besitzern und $2,8 \%$ von Ficusexponierten Büroangestellten positive Prickteste und RAST auf. Schließlich wurde in einer Serie von 156 Patienten mit Atemwegsbeschwerden bei 7,5\% ein positiver Pricktest gefunden. Seither fordern einige Allergologen, Ficus-benjamina-Extrakt bei allen $\mathrm{Pa}-$ tienten mit unklaren respiratorischen Symptomen zu testen.

\section{Kasuistik einer Kreuzallergie}

Den Patienten droht jedoch nicht nur Gefahr von der Zimmerpflanze. Aus Madrid wird jetzt der Fall einer 36jährigen Allergikerin berichtet, die nach dem Verzehr von Feigen und
Kiwis mehrmals ein Angioödem entwickelte. Die Frau war seit 1993 wegen einer Allergie auf Pollen des Olivenbaums in Behandlung. Die asthmatischen Beschwerden, die ganzjährig auftraten, besserten sich auch nach einer Immuntherapie nicht. 1996 berichtete sie, daß sich die Symptome regelmäßig verschlechterten, wenn sie die Blätter ihres Ficus benjamina wusch. Auf die Berührung der Blätter reagierte sie mit Juckreiz und Rötung an den Händen. Ein Angioödem entwickelte sie erstmals 1995 nach dem Genuß einer frischen Feige. Später folgten weitere Fälle nach dem Verzehr von Kiwis und trockenen Feigen.

Die allergologische Untersuchung bestätigte den Verdacht einer Kreuzsensibilisierung. Bei der Frau ließen sich sowohl Allergene gegen Latex von F. benjamina, Feigen und Kiwis nachweisen. Eine bronchiale Provokation mit F.-benjamina-Latex war zweimal positiv. Innerhalb von 21 Stunden kam es zu einem Anstieg des eosinophilen kationischen Proteins, so daß vermutlich eine Aktivierung der Eosinophilen vorlag. Im CAP-Test wurde eine 95\%ige Inhibition von Feigen und eine 57\%ige Inhibition von $\mathrm{Pa}$ pain nachgewiesen.

\section{Keine Kreuzreaktionen mit Kautschuk-Baum}

Glücklicherweise ergaben die Tests keine Kreuzreaktionen zwischen dem Ficus-Allergen und dem Papain in der Latexmilch des Kautschukbaums (Hevea brasiliensis). Offenbar sind unterschiedliche Epitope betroffen. Die Madrider Arbeitsgruppe hält allerdings dennoch nicht für ausgeschlossen, daß sich derartige Kreuzsensibilisierungen entwickeln können. (rme)

Quelle: Díez-Gomez ML et al.: Asthma caused by Ficus benjamana latex: evidence of cross-eactivity with fig fruit and 